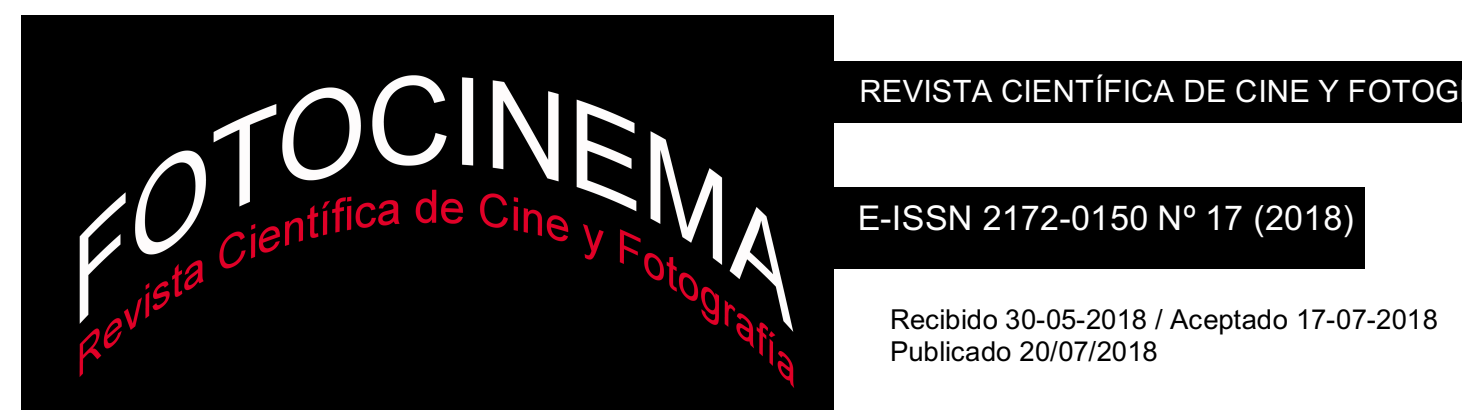

\title{
"Registrar a imagem do povo e devolvê-la a povo". Imágenes por y para una revolución: Mozambique y el cine
}

\section{Registering the image of people to bring back to the people. Images by and for the revolution: Mozambique and the cinema}

\author{
José Antonio Jiménez de las Heras \\ Universidad Complutense de Madrid, España \\ joseantj@ucm.es \\ Ricardo Jimeno Aranda \\ Universidad Complutense de Madrid, España \\ rijimeno@ucm.es
}

\section{Resumen:}

Tan sólo en dos momentos históricos el cine y la revolución han asumido una simbiosis que les ha hecho ir de la mano en una evolución conjunta. El primero de esos momentos es bien conocido: la revolución rusa y la vanguardia cinematográfica soviética. El otro momento histórico bebe, sin duda, del anterior, pero es casi desconocido y responde a la independencia de Mozambique y al nacimiento de la nación, que supuso también el nacimiento del cine mozambiqueño como instrumento de educación y propaganda ideológica inseparable de la propia evolución del país. Lo que aquí interesa es analizar el devenir de esa revolución cinematográfica e histórica, que termina en las filmografías de dos cineastas unidos a la historia del cine mozambiqueño: Licinio Azevedo y Margarida Cardoso. Protagonista Azevedo y testigo privilegiado Cardoso de la evolución del cine de Mozambique, y de su transición del documental a la ficción, ambos presentan filmografías apasionantes sobre una revolución cinematográfica e histórica que merece ser recordada. Caminos cruzados que hablan de revolución, memoria, fracaso y ausencia, mediante la construcción de universos personales entreverados con la propia historia social y política de Mozambique.

\begin{abstract}
:
Only in two historical moments, film and revolution have assumed a symbiosis that has made them go together in a joint evolution. The first of these moments is well known: the Russian Revolution and the Soviet cinematographic avant-garde. The other historical moment is undoubtedly influenced by the previous one, but it is almost unknown and responds to the independence of Mozambique, the birth of this nation, which meant also the birth of Mozambican film. This film emerged as an instrument of education and ideological propaganda, closely indeed to the evolution of the country. This article focuses in the analysis of the evolution of that cinematographic and historical revolution and in the filmographies of two filmmakers linked to the history of Mozambican cinema: Licinio Azevedo and Margarida Cardoso; Azevedo develops a first role, and Cardoso the part of a privileged witness of the evolution of Mozambique's cinema, and of his transition from documentary to fiction. Both filmmakers present exciting filmographies about a cinematographic and historical revolution that deserves to be considered. Both represent crossed roads that speak of revolution, memory, failure and absence, through the construction of personal universes intertwined with the social and political history of Mozambique.
\end{abstract}

Palabras clave: Mozambique; revolución; cine; FRELIMO; documental; narrativa.

Keywords: Mozambique; Revolution; Cinema; FRELIMO; Documentary; Narrative. 
Al querido Mozambique y a los amigos de sus tierras lejanas

"En el mundo al que combato muero, en el mundo por el que lucho nazco" (Mia Couto)

\section{Introducción y marco teórico}

La revolución y el cine han protagonizado juntos muchos momentos históricos, pero en tan sólo dos ocasiones se ha producido un trasvase simbiótico entre los dos, de forma que ambos hayan nacido, crecido y evolucionado juntos hasta una ruptura anunciada e inevitable desde su propio nacimiento.

El primer momento histórico en que esto ocurrió fue entre 1917 y el final de la década de los 20 en el siglo pasado: el estallido de la revolución rusa propició el nacimiento de una vanguardia cinematográfica que puso el talento de sus cineastas y de sus obras al servicio de la revolución: una aventura estética, narrativa, vital e ideológica que no hubiera existido sin la revolución; de la misma forma que la revolución no hubiera sido la misma sin el cine de la vanguardia soviética.

Cuando menos resulta llamativo que este fenómeno se repitiera, casi de la misma forma -aunque con notables matices de diferencia-, unas cuantas décadas más tarde, en un lugar tan remoto y diferente a la URSS como la República Popular de Mozambique (1975-1992).

La primera diferencia es el desconocimiento general de esta nueva aventura cinematográfica, histórica e ideológica a un mismo tiempo. Y es que, más allá de lo ocurrido en la URSS, el cine mozambiqueño nacerá con la propia nación mozambiqueña. Un cine que será documental por imposición revolucionaria y que, a duras penas, avanzará hacia la ficción por la voluntad de algunos cineastas. Una evolución ejemplificada en dos cineastas de referencia en Mozambique: Licinio Azevedo y Margarida Cardoso. Para ellos la ficción será una nueva forma de abordar la realidad más allá del marco documental cuando éste se les quede estrecho para contener su mirada personal; una mirada a la vez, sobre sí mismos y también sobre la historia de 
un país que ha forjado la identidad personal de ambos mediante la revolución y a través de su relación con las imágenes documentales que la testimonian (de muchas de las cuales Azevedo es responsable y Cardoso obsesiva observadora), cuyo sentido histórico y personal les exige una voraz y progresiva necesidad de reflexión.

\section{Contexto histórico: Mozambique, una revolución con imágenes}

El mejor resumen respecto al panorama histórico conjunto de cine y revolución en Mozambique, nos lo ofrece Raquel Schefer en un artículo sobre Ruy Guerra y su quehacer en el cine mozambiqueño. En él, Schefer periodiza en las siguientes fases la evolución del cine mozambiqueño, en función del momento histórico-ideológico:

El cine revolucionario mozambiqueño tiene tres fases: pre-cine (1966-197475), anterior a la independencia del país, una categoría que está unida, temporal y materialmente, a la afirmación de una Estética de la Contingencia o a una "Estética de lo Posible", de acuerdo a lo afirmado por Guerra (Simao \& Schefer, 2011); la Estética de la liberación (1975/1976-1984) correspondiente al Instituto Nacional de Cine (INC), institución creada en 1976 y que tiene dos períodos -el período de institución (1975/1976-1979) y el período de destitución (1979/1980-1984) del lenguaje cinematográfico; y el período de Realismo Socialista (1984/1985-1987) (Schefer, 2016, p. 56).

\subsection{El cine de guerrilla}

Cuando Schefer se refería a un período pre-cinematográfico en Mozambique, correspondiente a ese "cine de la contingencia o de lo posible" es algo textual: no existe cine previo a la revolución en Mozambique. Sí existía, por supuesto, una infraestructura de distribución y proyección en Mozambique desde una perspectiva colonial (ver capítulos 10 y 11 en Convents, 2011), pero no había producción alguna. De esta forma, la "precinematografía” de Mozambique ya va a estar unida a la lucha de liberación y a la guerrilla. Serán los propios guerrilleros del FRELIMO (Frente de Liberación de Mozambique), creado por Eduardo Mondlane, padre de la lucha de liberación mozambiqueña, 
quienes empiecen a filmar las primeras imágenes de la contienda y, por lo tanto, las primeras imágenes del cine de Mozambique, imágenes hoy perdidas. Testigo privilegiado de aquel momento fue José Luis Cabaço, Ministro de Información de Mozambique en el periodo previo a la muerte de Samora Machel, el líder del FRELIMO y primer presidente de Mozambique. Cabaço narra lo siguiente:

En 1969, El Departamento de Información y Propaganda (DIP) del FRELIMO -el movimiento socialista que conduciría a la lucha por la independencia- creaba en su organigrama un sector de imagen dirigido por José Soares, un guerrillero que tuvo una breve formación como fotógrafo. El departamento recibió una donación de equipamiento en 8 y $16 \mathrm{~mm}$, pero su operación era algo muy dificultoso para cuadros con tan poca formación, así que su misión fue entonces la de registro fotográfico (Cabaço, 2017, p. 91).

Las pocas imágenes tomadas por los guerrilleros del FRELIMO fueron completadas por cineastas y creadores extranjeros de otros ámbitos, como el teatral, con una posición ideológica que les llevó a acompañar a los mozambiqueños en su lucha de liberación. Encontramos aportaciones como las de Dragutin Popovic que en 1965 visitó la zona de conflicto realizando un breve documental titulado Venceremos, el primero sobre las actividades guerrilleras del FRELIMO, pero que apenas tuvo impacto internacional, sobre todo en occidente (Cabaço, 2017, p.91). Otras aportaciones extranjeras serán las realizadas por Margaret Dickinson con Behind the Lines (1972), Étudier, produier, combattre (1973) realizada por el Grupo Cinéthique y, sobre todo, las realizadas por Robert Van Lierop.

Lierop era un cineasta norteamericano con orígenes surineses, por parte de padre, que en base a ellos desarrollará un intenso interés por África y en contra de los regímenes racistas, como el de África del Sur. Lierop cineasta militante terminará en Mozambique por invitación de Eduardo Mondlane (Convents, 2011, p. 350) y realizará un filme que se titulará A luta continua (1971)1. El filme llegará a estrenarse en Nueva York ante 2.500 espectadores y tendrá un éxito relativo con exhibición en diferentes países occidentales y en

\footnotetext{
${ }^{1}$ https://www.youtube.com/watch?v=NUdeF2KNeCg\&feature=youtu.be).
} 
otros como Cuba, Chile o Jamaica, además de en numerosos países africanos como filme de propaganda revolucionaria y de liberación. La película logrará “dar un rostro al FRELIMO” (Convents, 2011, p. 351) y servirá como apoyo a su causa.

El cine de guerrilla, como reconocerá el propio Ex Ministro Cabaço será “más sobre los mozambiqueños que películas mozambiqueñas” (Convents, 2011, p. 352). De esta forma, Soares y su compañero Torohate, responsables del área de cine del FRELIMO, se dedicarán no tanto a filmar como a acompañar a cineastas extranjeros, interesados y comprometidos con la revolución. Gracias a ello, el cineasta italiano Franco Cigarini producirá un reportaje llamado Dieci giorni con $i$ guerriglieri del Mozambico libero (1972) ${ }^{2}$ realizado en zonas liberadas por el FRELIMO, en el norte de Mozambique. Cabaço contará lo siguiente sobre esta última experiencia:

El filme surgió como respuesta de los italianos a un comunicado hecho por el embajador de Portugal en Roma negando la existencia de zonas liberadas en Mozambique intentando desactivar cualquier acción de solidaridad (...) El filme fue prueba evidente de la operacionalidad y dimensiones que había adquirido la lucha de liberación y, por otro lado, demostró la vitalidad de la resistencia de los mozambiqueños a la ocupación extranjera (Cabaço, 2017, p. 91)

Todo lo anterior refuerza la tesis de que el cine, la revolución y la nación en Mozambique son una misma cosa sin la cual las demás no podrían caminar, en un hecho único en la historia del cine y la revolución. Una unión que además forjará sus lazos a través del reflejo directo de la realidad, mediante su captación a través de la cámara, lo que hará que sea el documental el arma de lucha única y prioritaria por la que el nuevo estado apostará.

\subsection{El nacimiento del cine en Mozambique. La creación del INC y los primeros documentales}

El 25 de junio de 1975 nace el nuevo estado mozambiqueño: la República Popular de Mozambique. No han sido pocas las dificultades. La Revolución

\footnotetext{
${ }^{2}$ https://www.youtube.com/watch?v=nIQZgNbDEwc\&feature=youtu.be
} 
de los Claveles en abril del 74 que acaba con el régimen dictatorial del General Salazar (el Estado Novo, 1933-1974, con Salazar de presidente desde el 51), junto a la intensificación de las acciones del FRELIMO en mayo, llevarán a un alto el fuego y el inicio de las negociaciones en septiembre de ese mismo año; entre ese momento y hasta la fecha de nacimiento del nuevo estado revolucionario, más de 150.000 personas abandonarán el país, la mayoría técnicos superiores, lo que supondrá un enorme handicap para el nuevo estado.

Las imágenes que dan inicio al documental de Margarida Cardoso Kuxa Kanema (2003) documentan aquel 25 de junio y reflejan la idea de que el cine ha de ser un instrumento esencial para la transformación social mozambiqueña, hacia ese "Hombre Nuevo" del que habla el FRELIMO y su lider Samora Machel, primer presidente de Mozambique: "Nosotros queremos crear un Homem Novo. Queremos a futuros revolucionarios. Queremos crear una nueva mentalidad libre con nuestra propia personalidad" (Machel citado por Manjate, 2017, P.113). Pero ese "Hombre nuevo" típico de los estados socialistas, tendrá muchas aristas y desviaciones autoritarias que provocarán conflictos. Esa idea del "Hombre Nuevo" tendrá en Mozambique un cariz de unificación forzosa que niega las raíces del propio pueblo:

El Mozambicano Novo o el Homem Novo, no es un africano unido a su cultura local y propia, si no a un socialismo universal y a un nacionalismo mozambiqueño. En la práctica eso significa que el gobierno desenvolverá una política para construir esta nueva identidad que supone una crítica a las estructuras tradicionales (Convents, 2011, p. 358).

Samora Machel será quien considere el cine y el documental como la herramienta transformadora y de propaganda esencial para ese "Hombre Nuevo”, ante una población en su mayoría analfabeta y que llega a hablar más de 40 dialectos distintos, sobre todo en el norte del país, la zona más pobre e infradesarrollada. De esta manera, el cine y, en concreto, el documental y su desarrollo, se convierten en un asunto de estado, esencial en el curso revolucionario. 


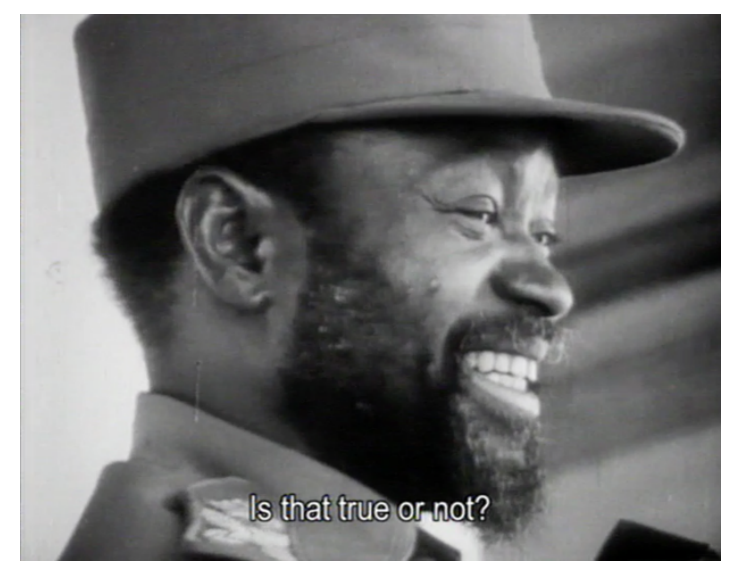

F1. Samora Machel primer presidente República Popular de Mozambique. Kuxa Kanema (Cardoso, 2003) (C) ICP.

La creación del Instituto Nacional del Cine (INC) y los primeros proyectos documentales mozambiqueños, es decir, concebidos y realizados por mozambiqueños, irán en paralelo. Pero dada la escasa formación de los nuevos cineastas mozambiqueños, la intervención de extranjeros será esencial para el arranque del cine en Mozambique.

El INC nacerá en 1975, tras la proclamación de la República Popular, como Servicio Nacional de Cinema (SNC) (Convents, 2011, p. 437) ocupando un edificio en el centro de la capital, Maputo, antigua Lourenço Marques. Los primeros encargos del INC van a ser dos documentales que serán codirigidos por mozambiqueños y extranjeros. Los dos primeros serán Um ano de independencia (1976), codirigido por el brasileño Fernando Silva y por el mozambiqueño Carlos Patraquim -colaborador de Licinio Azevedo en toda su carrera y figura clave del cine en Mozambique.

El segundo será el más célebre, 25, en conmemoración de la fecha de la independencia. Así lo señalará, su principal responsable (junto a Celso Lucas), el también brasileño José (Ze) Celso Martínez Correa:

Surge la idea de dar al filme el título de 25 como una referencia a fechas destacadas: el 25 de junio de 1962, fecha fundacional del FRELIMO; 25 de septiembre de 1964, fecha en que fue disparado el primer tiro de la insurrección del país; el 25 de abril, como final del Estado Novo portugués. Así, el filme se convirtió en una duplicidad que mostraba la "fiesta" del 25 de junio y la "anti-fiesta", en referencia a las dificultades del pueblo 
mozambiqueño que se había visto envuelto en estos otros acontecimientos durante 3 décadas (Silva citado por Soranz, 2014, p. 152).

La propia concepción del filme parecía entrar en conflicto con la política del FRELIMO, pues los directores mostraban "una imaginación política sobre Mozambique que podía ser interpretada como una primera crítica: el gobierno es diferente del pueblo" (Convents, 2011, p. 358). Así, 25 se va a convertir en un primer "fracaso" que demuestra el inevitable divorcio entre los artistas/creadores y las autoridades revolucionarias que velan por la "pureza” de la revolución. Para Celso Correa el cine debiera ser:

Un cine popular, revolucionario, un modelo que no estuviese ligado a los conocidos modelos de cine hegemónico hollywoodiense o del cine de arte europeo, algo perfectamente alineado con las políticas del FRELIMO, pero sin embargo ese ideal de un cine revolucionario hecho por y para los mozambiqueños, con bases populares, es un cine que entró en contradicción con la propia concepción del INC (Soranz, 2014, p. 152).

Ze Celso, que había huido de Brasil y que "había tenido experiencias de persecución y censura durante la dictadura militar” (Soranz, 2014, p. 153), llegaba a Mozambique con la idea de encontrar "un estímulo revolucionario que abriera perspectivas sociales y culturales para la construcción de un nuevo país" (Soranz, 2014, p. 153). Sin embargo, tras finalizar la postproducción de 25 en Inglaterra, Celso Correa encontrará un país en el que el divorcio entre sus ideas y el estado revolucionario será cada vez mayor, lo que provocará que abandone Mozambique en 1978 para no volver.

\subsection{Kuxa Kanema y la experiencia de Ruy Guerra en Mozambique. Jean Luc Godard y Jean Rouch: experimentos fallidos}

Volviendo a la cronología de Raquel Schefer nos encontraríamos en el período de "Institución" del INC, que pasa a tomar este nombre de forma definitiva en 1976. El INC va a ser el encargado de constituir el cine mozambiqueño basado en el documental y a él van a estar unidos varias figuras básicas de la historia de este cine. Ya hemos nombrado antes a Luis Carlos Patraquim que además de realizar Um ano de independencia (1976), va a ser el argumentista principal y coordinador de guiones del INC y, junto 
al director del mismo y productor Pedro Pimienta van a ser los responsables del informativo semanal Kuxa Kanema.

Kuxa Kanema significa literalmente "nacimiento del cine" y es la unión de dos palabras en dialectos mozambiqueños: Kuxa en dialecto Rhonga que significa "nacimiento" y Kanema en dialecto Macua que significa "imagen” (Soranz, 2014, p. 154). Kuxa Kanema iniciará su andadura en los años 1977/1978, en los que se realizarán 9 documentales dentro de la serie. Uno de los más destacados será el realizado y dirigido por Fernando Silva, titulado Massacre de Nyazonia. En él se narra el ataque del ejército de Rhodesia al campamento de Nyazonia. Patraquim, guionista del mismo, y Silva deciden no introducir ningún comentario en off al mismo y mostrar sólo las imágenes del horror dejadas por la aviación de Rhodesia. En una muestra más de esa vinculación entre el cine, la revolución y el estado, Samora Machel mostrará ante la Asamblea General de la ONU, en su discurso de 1977, estas imágenes como prueba fehaciente de la agresión de los regímenes racistas de Rhodesia y África del Sur hacia Mozambique, produciendo una enorme conmoción entre los presentes (Convents, 2011, p. 410).

En paralelo a la iniciativa de Kuxa Kanema el INC seguía produciendo documentales como el realizado por el director brasileño Murilo Salles junto al escritor Luis Bernardo Honwana, titulado Estas sao as armas (1977)3 .

En sus 50 minutos, el documental se centra también en los raids aéreos de la aviación de Rhodesia durante el intento de invasión de Mozambique por el régimen de Ian Smith en 1977. Con este filme el FRELIMO quería "mostrar al pueblo el concepto de "Imperialismo" dentro de la doctrina marxista/leninista del poder en Mozambique" (Convents, 2011, p. 443).

Volviendo a Kuxa Kanema su actividad se estabilizará y estandarizará a partir de 1981 y hasta 1983, produciendo semanalmente 10 minutos de programa, gracias en buena parte a la presencia de Ruy Guerra en

\footnotetext{
${ }^{3}$ https://www.youtube.com/watch?v=ZDoxEH7ozdo\&feature=youtu.be. Para entender la aventura de este documental es imprescindible acudir al artículo dedicado por el estudioso del cine mozambiqueño Robert Stock al análisis de "Esta sao as armas" (Stock, 2016, p. 7591)
} 
Mozambique, a partir de 1978, convidado por el INC y el gobierno de Mozambique para ayudar al establecimiento de las actividades del Instituto.

El caso de Guerra es significativo e interesante. Nacido en Mozambique en 1931, en la antigua Lourenço Marques, Guerra se marchará a Brasil por cuestiones políticas y allí será uno de los fundadores y principales representantes del llamado "Novo Cinema Brasileiro", una de las más importantes manifestaciones dentro del movimiento de los "Cines nacionales". Cuando Guerra es invitado a volver a su país de origen es ya un reputado cineasta internacional que retorna llevado por una responsabilidad histórica y por un idealismo que tampoco se engaña sobre las dificultades que allí va a encontrar -Guerra se enfrentaba en su propio país a un régimen autoritario, en este caso de derechas.

Las razones de Ruy Guerra para acudir a la llamada de sus compatriotas y del nuevo gobierno del FRELIMO se expresan con precisión en sus siguientes palabras:

En aquella época trabajar para el cine mozambiqueño era algo fácil, y al mismo tiempo difícil y complicado. Complicado porque estábamos iniciando la actividad del INC y no había nada. Y cuando no se tiene nada las cosas son al mismo tiempo fáciles y complicadas. Son fáciles porque nadie te obliga a luchar contra ninguna estructura establecida que eventualmente estaría equivocada. Y había un aspecto que marcaba toda diferencia: una fortísima voluntad política de crear un cine mozambiqueño (...) Esa simple fase determina todo, porque sin voluntad política no hay cine que se construya y que sobreviva en ningún país (Lopes, 2016, p. 10)

Lo anterior no significa que el entusiasmo de Guerra no le dejara ver las dificultades que presentaba que un artista, conocedor de la represión de un estado totalitario, se pusiera al servicio de un régimen socialista; dificultades que él mismo le transmitió al entonces Ministro de Información, tal como expresa el propio Ruy Guerra a Margarida Cardoso en la entrevista que esta realizó con el director para su documental Kuxa Kanema (Cardoso, 2003).

La labor de Guerra fue ingente, llevando técnicos brasileños para la formación de cuadros técnicos; realizando él mismo varios episodios de Kuxa 
Kanema -será él quien invite a Licinio Azevedo a ir a Mozambique para participar en el programa; organizando y estandarizando la producción del INC y también con la creación de un sistema de exhibición que se llamará "Cinema Móvil” y que recordará, de forma inevitable a las experiencias de Dziga Vertov y Alexander Medvdekine con sus cines-tren, en los que recorrían la nueva patria soviética aleccionando a las masas.

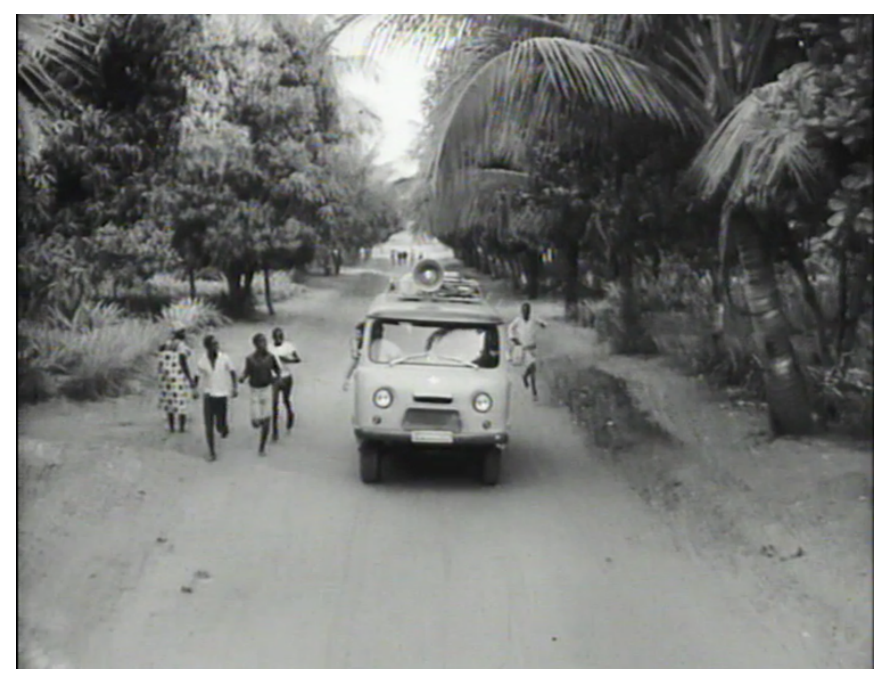

F2. Una de las furgonetas del Cinema Móvil llegando a una aldea. Kuxa Kanema (Cardoso, 2003) (C) ICP.

Entre 1976 y 1978 se establecerá en la provincia de Beira, bajo la dirección de José Cardoso (Convents, 2011, p. 473), un centro de formación de operadores y la base de operaciones en el norte del país del llamado "Cinema Móvil". Este proyecto, apoyado por Ruy Guerra y desarrollado durante su larga estancia en Mozambique, funcionará con una serie de furgonetas equipadas con material de filmación y proyección que recorren las aldeas proyectando los diferentes episodios de Kuxa Kanema y otros documentales para la educación (y el adoctrinamiento) de las masas campesinas.

Será en la "Segunda Conferencia de Trabajo Ideológico Nacional", celebrada en Beira en junio de 1978, cuando los cuadros del FRELIMO apuesten por el “Cinema Móvil” antes que por la creación de salas cinematográficas estables en la zona rural del país (Convents, 2011, p. 423).

La aportación definitiva de Ruy Guerra al cine mozambiqueño será la realización del que se considera el primer largometraje de Mozambique: 
Mueda, Memoria e Massacre (1979)4. El filme está basado en los sucesos ocurridos el 16 de junio de 1960, que desembocaron en una masacre a manos del ejército colonial contra los campesinos y cooperativistas de la localidad de Mueda en Cabo Delgado (Convents, 2011, p. 463). Guerra, al cual había llegado la historia a través de uno de sus ayudantes, va a filmar un docudrama que se centra en la representación que realizan todos los años los campesinos de Mueda, en recuerdo de aquella masacre. Es evidente que los elementos etnográficos y la reflexión social y política inherente a esta representación tenían que llamar la atención de un cineasta como guerra. Sin embargo, una vez terminado el filme y visionado por el Ministro de Información de Mozambique, Jorge Rebelo, la versión de Guerra fue rechazada. Tras una reunión entre el cineasta y el ministro, el filme fue censurado y parcialmente rehecho y remontado, sin participación de Guerra (Schefer, 2016, p. 56). Lo que Schefer afirma en otro artículo sobre el filme es que, en su versión original, se desviaba de la idea que tenía aparato del FRELIMO de lo que debía ser la representación cinematográfica de su política, y se centraba en exceso en el pueblo y en algunas de las representaciones Macondes tan presentes en la ceremonia: un desvío “indigenista" sancionado por la política oficial del FRELIMO (Schefer, 2012, p. 274).

Esta va a ser una de las razones por las que, con el transcurso del tiempo, Guerra abandone Mozambique: esa idea de "crear imágenes del pueblo para devolvérselas al pueblo" que animaba en teoría a los responsables de Kuxa Kanema queda en entredicho con sucesos como el de Mueda; así, el divorcio, inevitable, entre cine y revolución empieza a sustanciarse.

Ruy Guerra también va a tener un interesante choque teórico-práctico con dos cineastas extranjeros, invitados por el gobierno de Mozambique al país a desarrollar una serie de proyectos que si, en principio, son bien recibidos, a la larga resultarán por completo fallidos y entrarán en conflicto con el diseño global que Ruy Guerra intenta para la construcción de una industria cinematográfica en el país -a semejanza de Brasil.

\footnotetext{
${ }^{4}$ https://www.youtube.com/watch?v=m3BmEooggMU
} 
En el caso de Godard el gobierno mozambiqueño va a celebrar un concurso con la empresa del cineasta, Sonimage, para tratar de desarrollar un sistema de televisión en el país. Esto crea polémica puesto que algunos ven en la iniciativa "una cuestión meramente comercial" (Convents, 2011, p. 454). Los problemas van a surgir desde el principio:

La llegada de Godard en la práctica es un desastre, puesto que utiliza un equipamiento que no está adaptado a las condiciones locales. En lugar de continuar trabajando con vídeo, opta por el Super 8, que posteriormente es copiado de nuevo en vídeo mediante la técnica de telecinado (Convents, 2011, p. 454)

Los problemas irán en crescendo con la actuación anárquica de Godard. Parece claro que el cineasta está poco interesado en establecer una televisión y sí en no dejar pasar la oportunidad de "explorar nuevas formas narrativas, aprovechando que el país no tenía ningún contacto previo con la televisión, no estando contaminado por los típicos contenidos televisivos" (Soranz, 2014, p. 156). De esta forma, Godard quiere experimentar con una especie de “anti-televisión”, tal como lo define José Luis Cabaço a Margarida Cardoso en el documental Kuxa Kanema (Cardoso, 2003). Cabaço narra a la cineasta, en el transcurso de su entrevista, que Godard pretendía enseñar a los campesinos a utilizar las cámaras de vídeo que había llevado, para que luego ellos hicieran una televisión propia, manejando ellos mismos los complejos equipos: un proyecto que por múltiples razones y por sus dificultades intrínsecas era inviable.

Además de ello, Godard, en su línea provocadora de “enfant terrible”, realiza declaraciones contra el cine militante comparándolo "con las producciones turísticas" y denunciando su "falta de creatividad" (Convents, 2011, p. 459), convirtiéndose en un personaje cada vez más incómodo para el FRELIMO. A esas alturas, y sin ningún resultado por parte de Godard, tras más de un año de viajes a Mozambique, Ruy Guerra se posiciona en contra del proyecto y el gobierno mozambiqueño rescinde el contrato de Godard que abandona Mozambique para no volver.

El caso de Rouch será diferente, pero terminará provocando también un enfrentamiento político con el FRELIMO y creativo con Ruy Guerra. Rouch, 
cineasta etnográfico por excelencia, establece desde su laboratorio en Francia un acuerdo con la Universidade Eduardo Mondlane, la más importante de Mozambique. En ella pretende desarrollar una serie de talleres en relación con los que desarrolla en las universidades francesas, utilizando el Super 8, que considera como el formato perfecto, para sus experiencias cinematográficas (Soranz, 2014, p. 159). Ya la utilización del formato Super 8 va a entrar en conflicto con los formatos en 16 y $35 \mathrm{~mm}$ utilizados por Guerra en el cine mozambiqueño, en un intento de profesionalización, de acuerdo a la experiencia del propio Guerra como cineasta -en un intento real de construir una industria cinematográfica y no experiencias o experimentos teóricos aprovechando las circunstancias del país; esta última una posición de revolucionario burgués o de salón que parecen representar Rouch y Godard. La propuesta de Rouch era que:

Los mozambiqueños trabajarán ellos mismos con cámaras para filmar sus propias historias y su realidad. Pensaba que todo proceso de producción cinematográfica con especialistas en sonido, realización, en montaje, etc., se alteraba por completo con las nuevas tecnologías. Ya no son precisos varios especialistas (...). Pero, mientras tanto, Rouch recurre para sus propias producciones a esos especialistas en sonido, montaje y realización (Convents, 2011, p. 449)

Así, a pesar de una primigenia buena relación entre Rouch y Guerra, sus conceptos sobre el cine mozambiqueño y lo que éste debería ser difieren progresivamente hasta la ruptura. En cuanto al FRELIMO la idea de Rouch de "posibilitar la democratización de la producción de imágenes, resulta una idea demasiado ambiciosa para un régimen centralizado, en donde el gobierno pretende controlar completamente la información” (Convents, 2011, p. 459). De esta forma, la aventura de Rouch terminará en un nuevo fracaso que le hará abandonar, al igual que a Godard, el país de forma definitiva.

\subsection{Disolución y declive del cine mozambiqueño: 1984-1992}

Desde aproximadamente mitad de la década de los 80, el cine de Mozambique va a sufrir un vuelco definitivo. Se va a crear una nueva 
institución audiovisual: el Gabinete de Comunicación Social que se convierte a partir de 1978 en el Instituto de Comunicación Social (ICS) y que va a estar en íntima unión con la creación de una televisión mozambiqueña. En 1979, la llamada Televisión Experimental de Mozambique realiza emisiones de televisión por primera vez en el país, en el marco de la Feria Internacional de Maputo (Convents, 2011, p. 456). En 1980, el Ministro de Información Cabaço tomará la decisión de crear la Televisión Nacional.

Junto a esto nacerá en 1983/84 la productora público-privada Kanema, unida de nuevo a Ruy Guerra -su primer director será el brasileño Labi Mendonça, al que Guerra había traído al país. Guerra tendrá acciones de esta nueva empresa, que nace para reforzar la producción del INC, aunque no siempre estos esfuerzos llegan a buen término (Convents, 2011, p. 482-483).

En este panorama quien empieza a destacar es Licinio Azevedo. El antes guionista de Kuxa Kanema será el responsable para el ICS de la serie de programas Canal Zero. Durante 5 años Azevedo va a ser también el responsable del ICS y realizará este programa ganando numerosos premios internacionales y formándose como realizador y director (Convents, 2011, p. 477).

Al mismo tiempo, los cineastas mozambiqueños, en contra de la política oficial del FRELIMO, empiezan a interesarse por la ficción. La primera experiencia en este sentido va a ser abordada de nuevo por un cineasta extranjero.

La República Popular Yugoslava, como simpatizante del pueblo y el gobierno mozambiqueños, va a poner en marcha una superproducción, la primera rodada en suelo de Mozambique, titulada O tempo dos leopardos (Zdravko Velimirovic, 1985). El guion va a estar basado en un libro del propio Licinio Azevedo que se titula Relatos do povo armado y se centra en los años de la guerra de liberación, tomando el material de las crónicas periodísticas del cineasta. Patraquim y él serían los responsables del guion. Sin embargo, los buenos augurios se comienzan a torcer cuando ambos viajan a Belgrado para hablar del guion con el co-guionista yugoslavo. Tal como cuenta Azevedo a 
Margarida Cardos en Kuxa Kanema (Cardoso, 2003), al leer la versión retocada allí se encuentran con incongruencias como que la película empiece con la persecución de una guerrillera desnuda por la selva, que se salva al cruzar un río a nado - sin preocupación por los cocodrilos que infectan los ríos mozambiqueños- y a la que sus perseguidores dejan ir por su belleza; o que los yugoslavos se empeñen en un final épico, en donde las Fuerzas Aéreas del FRELIMO, inexistentes en la realidad -el FRELIMO no dispone ni de aviones ni de helicópteros-, rescaten en una gran secuencia de acción al jefe de los guerrilleros, preso por las fuerzas coloniales. Estos delirios y el tono triunfante e insoportablemente maniqueo del filme, junto a la mutua incomprensión de yugoslavos y mozambiqueños, hacen de esta una experiencia agridulce que no termina de ser satisfactoria para nadie.

Sin embargo, la experiencia acumulada hará a José Cardoso, uno de los cineastas con más experiencia de Mozambique, animarse con el primer filme de ficción 100\% mozambiqueño. En 1986 Cardoso realizará O vento sopra do norte, un filme que "debe hacer recordar el pasado" (Convents, 2011, p. 494). El filme no será una experiencia satisfactoria del todo para su director, pero rompe la tendencia oficialista del documental y abrirá, años después, el camino para un cine de ficción mozambiqueño representado, casi de forma exclusiva, por Licinio Azevedo.

Sin embargo, un trágico hecho va a cambiar el rumbo de la revolución y su cine, unidos en una simbiosis única hasta ese momento en la historia: en el año 1986, Samora Machel y el séquito que le acompaña se estrellarán en el avión presidencial, muriendo todos. La sombra de un magnicidio, organizado por sectores opositores dentro del FRELIMO, siempre ha planeado sobre este supuesto accidente. Lo cierto es que la muerte de Samora, férreo defensor del cine nacional, revolucionario y de estado, va a hacer que la política sobre este medio cambie, produciéndose un divorcio anunciado. El cine deja de ser prioritario para el FRELIMO y ya no será el medio de expresión del nuevo régimen.

En 1988 la producción de Mozambique parece encontrarse parada por completo. El vídeo sustituye al cine. Licinio Azevedo hará su primer 
largometraje utilizando este formato: A colheita do Diabo (Azevedo, 1988), película mezcla de ficción y documental, que traerá problemas al director: el actor protagonista, un auténtico revolucionario Makonde, con escarificaciones tribales en la cara -algo que recuperará para el Teniente Sete Maneiras en Comboio de Sal e Açucar-, le valió a Azevedo acusaciones de "etnicismo".

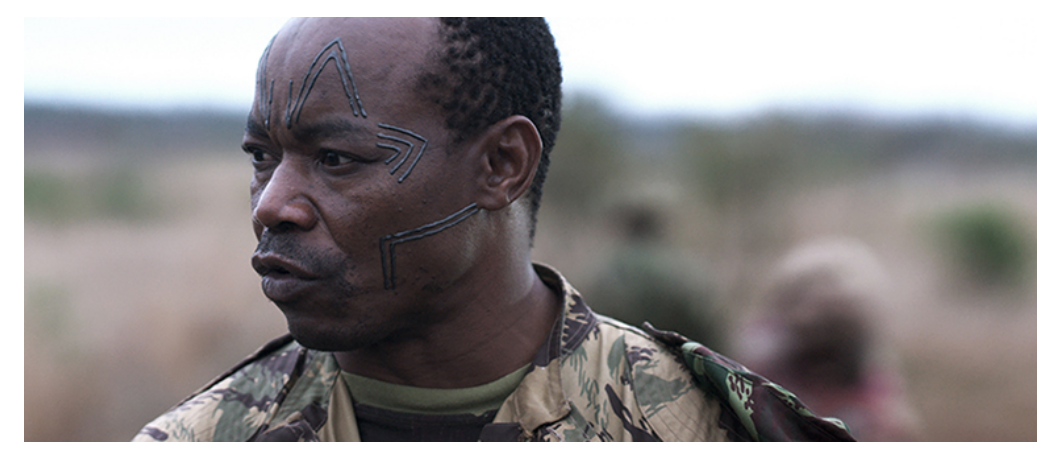

F3. El Comandante Sete Maneiras con escarificaciones rituales Makonde en el rostro.

Comboio de sal e açucar (Azevedo, 2016) (C) ICP.

La segunda tragedia y el definitivo entierro de la simbiosis entre cine y revolución, y que supuso la muerte simbólica (y casi real) del cine en Mozambique, fue el incendio que arrasó el INC y casi todos sus fondos documentales: una pérdida irreparable de la cual el cine mozambiqueño no se ha recuperado.

El auténtico panegírico de esta época no podía estar más que en boca de Ruy Guerra, que después de la muerte de Samora Machel abandonará Mozambique de forma definitiva. El padre del cine mozambiqueño (con permiso del propio Licinio Azevedo, que podría compartir dicha paternidad o, al menos, recoger y ampliar su legado) se expresará así al respecto:

Digo con la mayor sinceridad y simplicidad que no volví más por que sentí que, en Mozambique, desapareció esa voluntad política en relación al cine. Es más: por una cuestión afectiva que se vio desalentada por el asesinato [sic] del Presidente Samora Machel (Lopes, 2016, p. 11). 
3. Caminos cruzados: evolución de las trayectorias cinematográficas de Licinio Azevedo y Maragarida Cardoso

\subsection{Licinio Azevedo, "un país sin imágenes es un país sin memoria..."}

Licinio Azevedo (Porto Alegre, 1951) realizaba estas declaraciones en una larga entrevista realizada por dos jóvenes periodistas (Pereira \& Cabecinhas, 2016, p. 1036), y si las hemos elegido para encabezar un breve repaso a su filmografía es porque representan el espíritu de su cine, documental o ficción. Azevedo -como Margarida Cardoso en otro contexto- tiene una preocupación esencial: que su cine refleje una realidad vivida, que ayude a comprenderla a las generaciones futuras y que sirva de testimonio histórico. Desde su trabajo como periodista en Brasil que le llevará a enfrentarse con el régimen militar y tener que abandonar su país, hasta su llegada a Mozambique en 1976, en pleno conflicto del que fue testigo privilegiado y notario mayor, Azevedo se ha preocupado por la realidad y por dar testimonio de ella. Su inicial trabajo en Kuxa Kanema así lo testimonia y su trabajo en Canal Zero lo corrobora. Y esa voluntad de notario de la realidad queda expresada en sus palabras:

Me gusta hacer documentales sobre las cosas que acontecen en el momento. Sobre las cosas del pasado es muy difícil hacer documentales, entonces ese documental se transforma en un libro y el libro en un filme. Es lo que ocurrió con Virgem Margarida que era una fotografía, fue un documental y después se transformó en una película (Pereira \& Cabecinhas, 2016, p. 1030).

Virgem Margarida (Azevedo, 2011)5 es, como el propio director apunta, el epítome de su quehacer fílmico. En 1999, Azevedo realiza el documental $A$ última prostituta; Azevedo le contará a Margarida Cardoso, en el documental realizado por ésta Licinio Azevedo-Crónicas de Moçambique (2011), cómo una instantánea del fotógrafo mozambiqueño Ricardo Rangel, en que dos policías se llevan detenida a una prostituta, inspiró su documental sobre los campos de reeducación del FRELIMO (la parte más oscura de la creación del

\footnotetext{
${ }^{5}$ https://www.youtube.com/watch?v=DZlwSOXuyP8
} 
"Hombre Nuevo). Sin embargo, esta historia no se agotó para el cineasta y en Virgem Margarida la retoma completando una trilogía sobre la realidad, transtextualizada desde la foto hacia el documental, y por fin, en la ficción. Y es en el documental que sobre él realiza Margarida Cardoso donde su historia, de una manera metalingüística, se refiere a la propia historia de Mozambique testimoniada por sus imágenes: un concentrado Azevedo maneja unos recortes de periódico en busca de historias; de historias cotidianas que nos devuelvan una imagen que parte del documental para infectar la ficción sin abandonar nunca la realidad.

\subsection{Margarida Cardoso, la melancolía de la ausencia}

Si en el cine de Azevedo la dialéctica documental/ ficción está vinculada siempre al testimonio de la realidad, en el cine de Margarida Cardoso esa dialéctica está unida a la memoria, es decir, a la reflexión sobre la realidad a través del recuerdo, pero también mediante la ausencia de recuerdos. En un artículo acerca del llamado cine de la memoria, sus autores exponían que este cine está compuesto por películas que:

Se cuestionan acerca de la naturaleza de la memoria como objeto de representación y que indagan en la forma que ha de adoptar su enunciación. Estas películas resaltan el acto de recordar, presentándolo como el principal eje temático de la película, y no se centran tanto en lo recordado, en los eventos traídos al presente del protagonista de la narración (Rincón, Torregrosa \& Cuevas, 2017, 177).

El cine de Cardoso, sin duda, pone en primer término "la naturaleza de la memoria como objeto de representación" de la realidad: esa es la substancia expresiva del mismo. Pero su cine también se centra en "los eventos traídos al presente del protagonista de la narración”, en la medida en que estos le permiten reflexionar sobre la propia narración y la vinculación con su pasado, con el de su país de origen, Portugal, y con su patria de adopción y objeto de su ausencia, Mozambique, y el África colonial portuguesa. Y ahí está, de forma complementaria al cine de Azevedo, su necesaria dialéctica entre documental y ficción. 
Memoria y ausencia se dan la mano en toda su filmografía, ausencia de imágenes como en esos archivos desaparecidos en su documental sobre Kuxa Kanema (Cardoso, 2003) o ausencia de memoria, recuperada a través de las fotografías que muestran las atrocidades cometidas por las fuerzas coloniales en Mozambique durante la guerra de liberación, y en las que Evita (Beatriz Batarda, actriz fetiche que repetirá protagonismo en Yvonne Kane), ve la naturaleza de su marido en A Costa dos Murmurios (2004). Unas fotografías que establecen un juego entre ficción y realidad que se colará de igual forma en Yvonne Kane: la fotografía en la que Evita ve a su marido sujetar una cabeza decapitada empalada "es de hecho la superposición de la figura del actor en la que es una fotografía real de la guerra colonial” (Vieira, 2013, p. 80).

La ausencia de memoria, la ausencia de imágenes o la ausencia de personas del pasado, todo ello entremezclado, forma la realidad de los personajes de Margarida Cardoso. Una ausencia que instala sus narraciones, documentales o ficciones, en la melancolía de lo que fue, de lo que pudo ser o de lo que nunca llegó a ser. Y como plantea Vieira en su artículo sobre A Costa dos Murmurios, la autora consigue "mediante la creación de una presencia visual de la ausencia, revelar no sólo el desastroso impacto dejado por el colonialismo portugués en África, si no la violencia de ignorar esa experiencia” (Vieira, 2013, p. 83). Y es que esa ausencia de memoria la combate la directora con una mirada reflexiva y metalingüística a la realidad que mezcla de forma consciente elementos documentales (falsos o reales) con elementos ficcionales para enfrentarnos, como en el caso del cine de Azevedo, al testimonio histórico:

Siempre me interesé mucho por la historia y por la investigación, y fui hacia el documental porque lo primero que me apetecía hacer era explorar determinadas cosas del pasado, de una historia que tenía que ver con mis padres, con mi infancia, con la guerra colonial (Dias \& Cipriano, 2010, 134). 


\section{Estacion(es) termini: Comboio de sal e açucar e Yvonne Kane}

\subsection{Comboio de sal e açucar: simbiosis entre ficción y realidad}

La vinculación con la realidad del cine de Azevedo se demuestra en que todas sus realizaciones, documentales o no, se basan en historias reales. Y de la misma forma, el acercamiento a ellas es siempre desde lo real. Incluso en Comboio que parte de una novela escrita por el director, el sustrato es real, buscando siempre esa microhistoria que nos permita acceder a la historia con mayúsculas de Mozambique en sus últimos 40 años. Azevedo parte siempre del documental -del reportaje periodístico inclusive, en honor a su formación periodística- para llegar a la ficción. La base de su película es la siguiente:

Mozambique era un gran productor de azúcar, pero las plantaciones fueron destruidas [...] Entonces las mujeres compraban sal en el litoral y atravesaban el norte del país para ir a Malawi, venderla y comprar azúcar [...] era un viaje que podía no tener fin... el convoy hacía $700 \mathrm{~km}$... podía llevar un mes, dos meses, era atacado, se saboteaba la línea... y muchas de esas mujeres y otros pasajeros morían. Durante la guerra intenté conseguir dinero para hacer un documental, pero no lo logré (Pereira \& Cabecinhas, 2016, p. 1030).

La historia que cuenta Azevedo es la historia de la película, pues en ella reconstruye esta realidad con precisión de entomólogo. En su idea de que los documentales sólo pueden contar "las cosas que acontecen en el momento", Azevedo ha de recurrir a la ficción para abordar esta historia que muestra, como lo hacía en Virgem Margarida, los aspectos más desconocidos y humanos de la revolución en la que participó, vivió y que le desengañó.

Y es que el cine de Azevedo se vincula con el del norteamericano John Huston en dos aspectos básicos: su profundo humanismo y en un planteamiento vital en donde la aventura es la base de la existencia. Una aventura entendida, al igual que en Huston, como un indisoluble itinerario físico, al mismo tiempo que un itinerario moral. La vinculación con Huston no resulta extraña escuchando a Azevedo y su gusto por estructuras típicas del cine norteamericano: 
Mi concepción del cine es aquella en la que la cámara es un instrumento de acción... en la narrativa la cámara tiene un papel que cumplir, no puede ser estática, los movimientos de cámara son la transición de una escena a otra... por que transportan a los personajes a sus estados de espíritu (Pereira \& Cabecinhas, 2016, p. 1038)

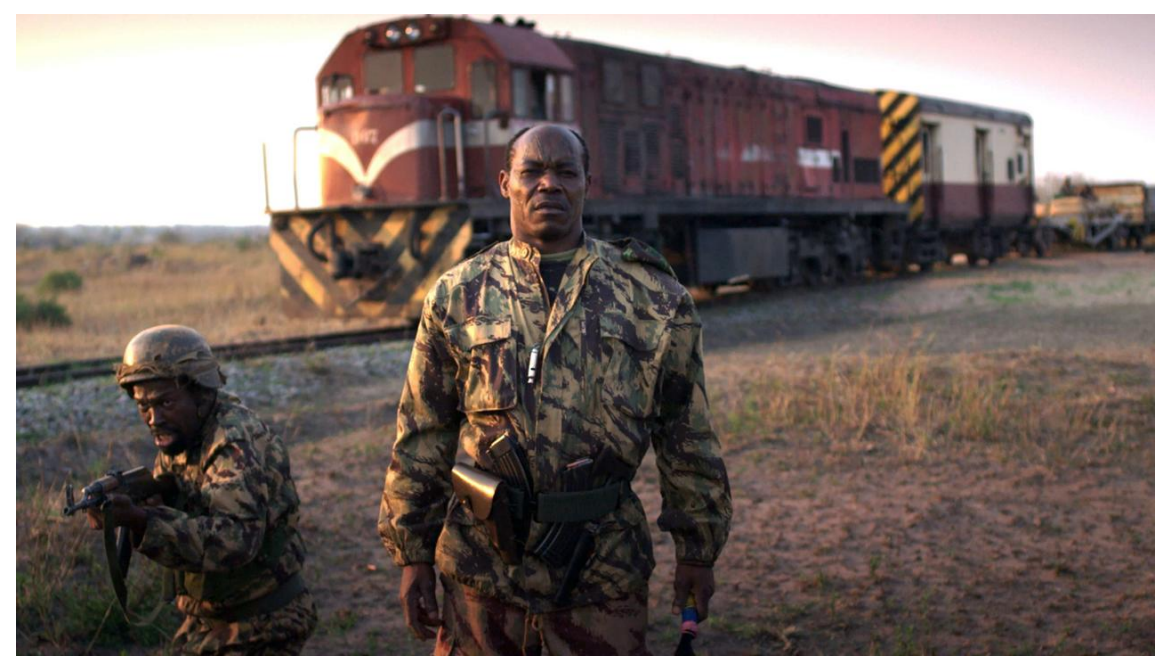

F4. Códigos genéricos: Western y “cine bélico moderno"; según su autor, el primer filme africano en abordar la temática. Comboio de sal e açucar (Azevedo, 2016) (C) ICP.

Esa concepción dinámica del cine está unida a la necesidad de un itinerario físico para que sus personajes puedan alcanzar con él esos "estados de espíritu”. Y ninguna metáfora mejor, desde los inicios del cine, que el de la locomotora arrastrando un convoy. Azevedo filma ese tren desde fuera, arrancando y parando, en numerosas ocasiones, porque al fin no es más que otro protagonista.

A pesar del esfuerzo de Azevedo por mantenerse pegado a lo real, algunos de sus personajes puedan resultar un tanto maniqueos: el teniente Tajar, un malvado prototípico de película del oeste; o su antagonista, el teniente Salomão representante de las virtudes absolutas, soldado amante de la paz y revolucionario con rostro humano. Sin embargo, nos ofrece uno de los más fascinantes y complejos retratos a través del Comandante Sete Maneiras. Con sus escarificaciones faciales el personaje nos remite al auténtico combatiente Makonde que protagonizó el primer largometraje de Azevedo ( $A$ colheita do Diabo) en un juego de espejos en donde la ficción refleja, una vez más la realidad. Este personaje que se enfrenta a las balas rechazándolas con su 
amuleto ritual (una cola de animal), es capaz de asesinar a sangre fría a un prisionero con un hacha tribal y puede resucitar tras pisar una mina, en un momento de realismo mágico que recuerda a García Márquez, ídolo de Azevedo, pero que también nos remite al novelista mozambiqueño Mia Couto y su realismo mágico africano.

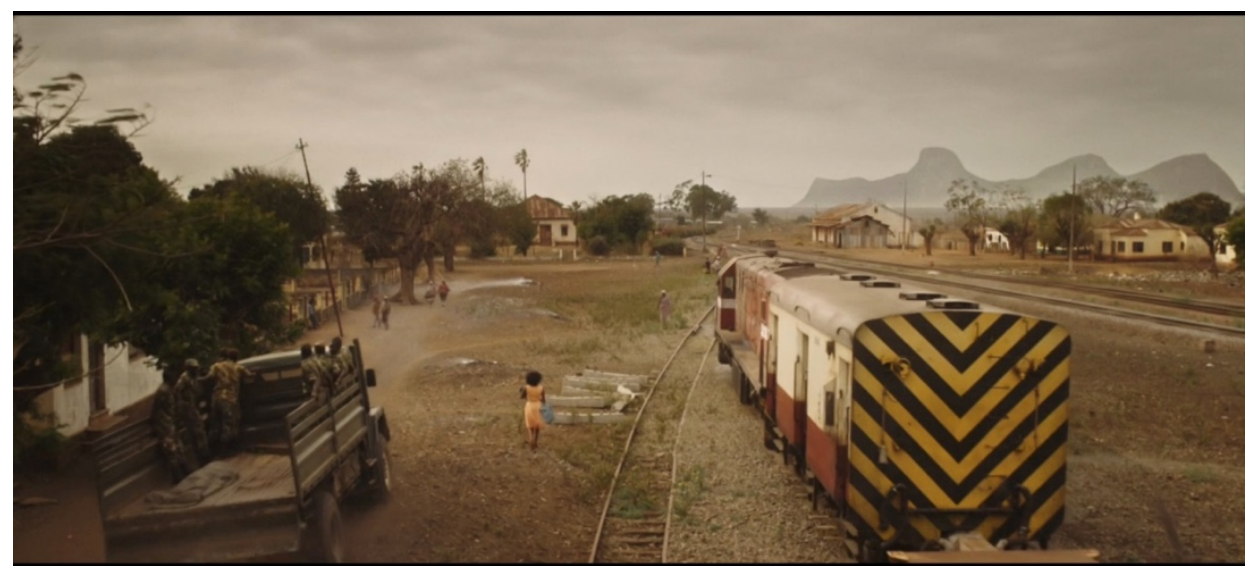

F5. El simbólico final: Rosa representa el futuro incierto de un Mozambique marcado por la guerra. Comboio de sal e açucar (Azevedo, 2016) (C) ICP.

Azevedo nos reserva lo mejor para el final. Rosa, la protagonista en este filme coral, ve morir a su amado Salomão en sus brazos, tras un duelo con aroma de western entre él y su némesis el teniente Tajar -los motivos visuales y las estructuras nos remiten de continuo a este género. Al llegar a su destino, con sus sueños rotos, se verá además responsable del niño que ha nacido en el convoy y que ha perdido a su madre en el último enfrentamiento con la guerrilla del RENAMO. La imagen final recogerá a Rosa en una encrucijada de caminos, avanzando por unas vías cruzadas, mientras que a uno de sus lados pasa el convoy que sigue su camino y al otro el camión que transporta el cadáver de su amado. Una imagen simbólica y real que remite al incierto futuro de Mozambique en tiempos de guerra, pero que nos refiere también su incierto futuro actual.

\subsection{Yvone Kane: un diálogo entre memoria e imagen}

En Yvonne Kane, al igual que en el resto de la filmografía de Margarida Cardoso, la realidad y los acontecimientos del pasado serán también los materiales básicos de construcción para su narración, pero siempre filtrados 
a través de la memoria. Es la enorme diferencia entre aquel que, como Azevedo, ha sido testigo privilegiado de la historia de la nación mozambiqueña y aquella que, como Cardoso, mira desde la atalaya del presente a un pasado anterior a esa nación, cuyo nacimiento provocó un desarraigo y una ausencia impregnada de melancolía que sólo puede curar el ejercicio de la memoria, a la vez personal e histórica, pues ambas son inseparables. En ese sentido no podemos sino estar de acuerdo en el planteamiento que hace Antonio da Silva, en su artículo sobre la película, insertando esta en un ejercicio de post-memoria:

La postmemoria caracteriza la experiencia de aquellos que crecieron dominados por narrativas anteriores a su nacimiento, en la que sus tardías historias son vehiculadas por los acontecimientos de las generaciones previas a ellos (las de sus padres) íntimamente unidas a traumáticos acontecimientos que ya no podrán ser entendidos o reconstruidos (Silva, 2016, p. 100).

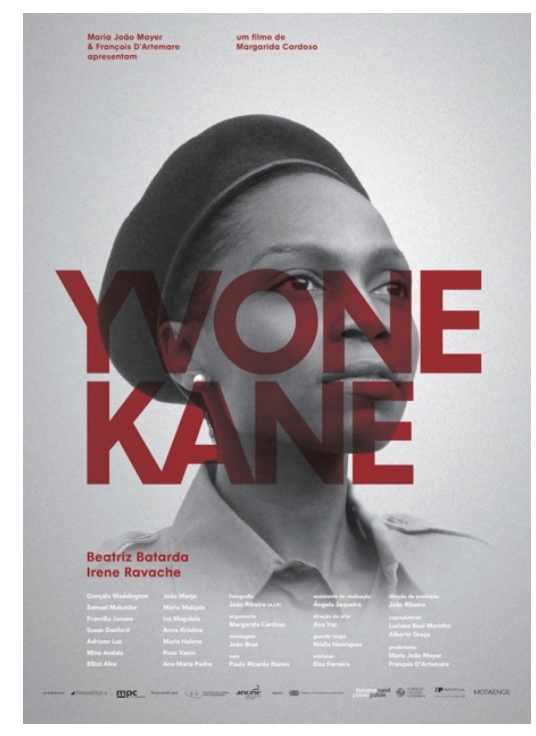

F6. Cartel publicitario. Yvonne Kane (Cardoso, 2014) (C) ICP.

Una definición que se ajusta al proceder de Cardoso desde su primer documental Natal 71, en donde un viejo disco encontrado en casa de su padre es el arranque de la narración, pero también a esta Yvonne Kane, profundamente personal. 


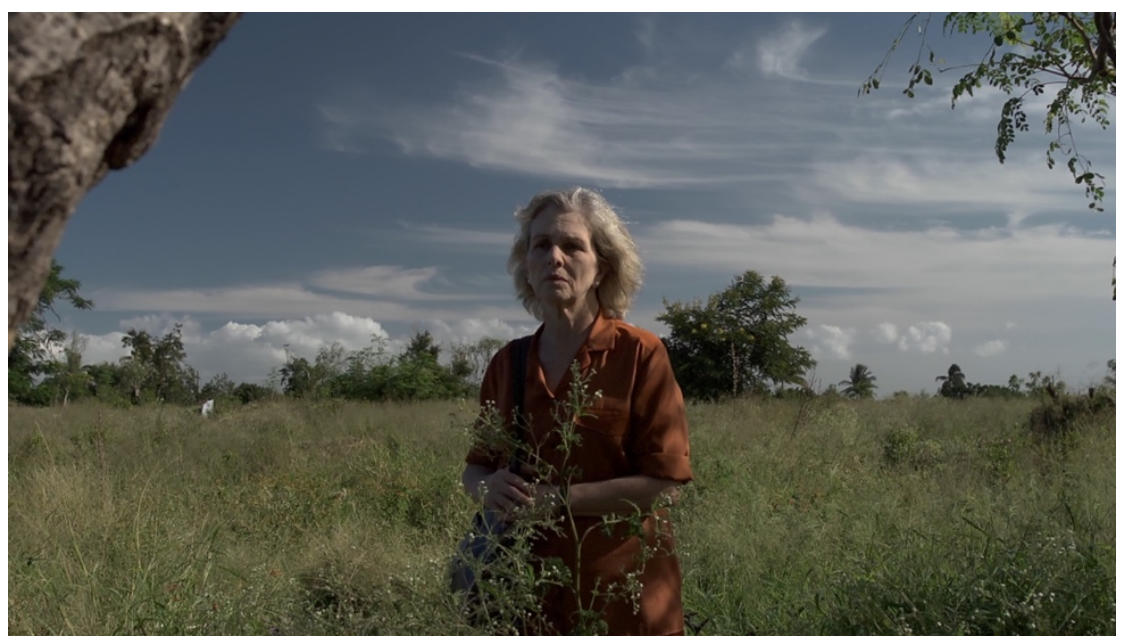

F7. La soledad de Sara, madre de Rita: ausencia, melancolía, fracaso y desilusión revolucionaria. Yvonne Kane (Cardoso, 2014) (C) ICP.

Rita (Beatriz Batarda, alter ego de Margarida Cardoso) vivirá en la ausencia: la ausencia del país de su infancia y adolescencia -país que Margarida Cardoso deja en la ficción indefinido, de forma voluntaria, en una mezcla de su Mozambique y Angola; la ausencia de su hija muerta (en off), en un melancólico plano que nunca nos muestra el rostro de la niña, convirtiéndose así en un reflejo especular de su madre, Rita, enfrentada a la ausencia de memoria de su propia niñez, enterrada en ese imaginario país mezcla de Mozambique y Angola. Y, por fin, la ausencia de esa madre, que envió a sus hijos lejos de la revolución y que se quedó a protagonizarla, generando otra doble ausencia en Rita: la de la figura materna y la de la experiencia no vivida que se recuerda casi con melancolía incurable.

En ese juego de espejos, Margarida Cardoso encuentra la perfecta metáfora que conecta realidad (documental) y ficción (reconstructiva): Rita pretenderá la reconstrucción de una post-memoria a través de la recuperación cuasi fantasmagórica de la figura mítica de Yvonne Kane, revolucionaria amiga de su madre y misteriosamente asesinada, sin que se sepa la verdad, reconstruida por el régimen para crear una "Virgen/Mártir" que recuerda la mentirosa leyenda de un Che Guevara en femenino. Y esa recuperación se hará mediante una (falsa) imagen documental construida con imágenes auténticas del Mozambique revolucionario: un planteamiento 
metalingüístico de indudable atractivo y conexión con la propia evolución del cine en Mozambique.

Y es que la figura de Yvonne Kane implica una construcción que invoca una realidad: ella nunca existió, pero remite a las figuras míticas de Josina Machel o de Sita Valles ${ }^{6}$, tal como reconoce la propia Margarida Cardoso (Lança, 2015). Los falsos documentales protagonizados por Yvonne remiten a las imágenes de Samora Machel a través de Kuxa Kanema y sirven de reflejo a Rita para revivir aquello que su madre vivió, pero a ella le fue negado; un ejercicio pues de postmemoria. Margarida Cardoso lo explica:

Al revelarse el pasado de Yvonne, que coincide con el pasado de varios países, Rita va entrando en el universo de la madre. Se separarán y no volverán a encontrarse más: la madre muere y es enterrada con el ruido del kuduro $^{7}$ y de las sierras mecánicas, (y Rita) va a ser enterrada metafóricamente en la piscina [...] Vamos a enterrar ese pasado, pero así es la vida [...] en la película era importante que no se supiese bien de dónde venían aquellas personas. La muerte de la hija al principio crea una especie de vacío. Y no vamos a saber quién mató a Yvonne, era sólo un pretexto (Lança, 2015)

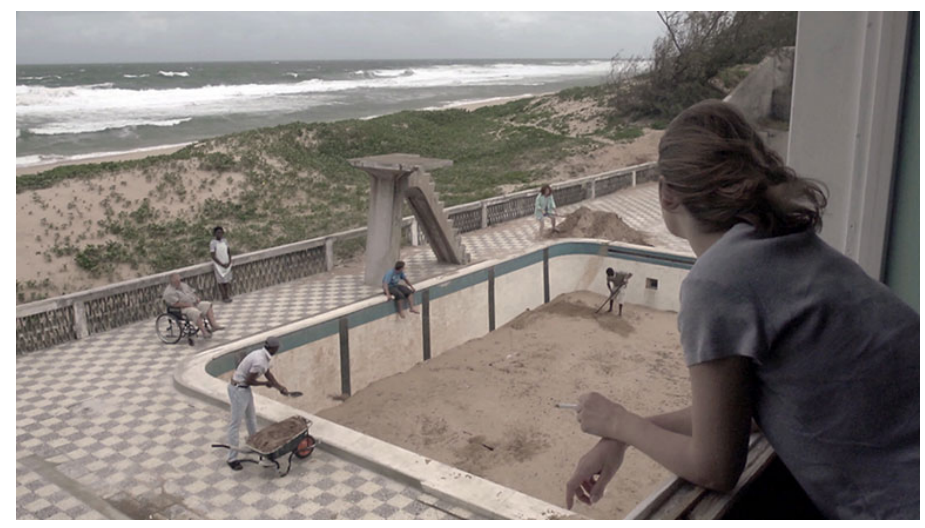

F8. El simbólico "entierro" de Rita tras ajustar cuentas con el pasado. Yvonne Kane (Cardoso, 2014) C ICP.

\footnotetext{
${ }^{6}$ Josina Machel era la esposa de Samora Machel y fue una figura de referencia junto a su esposo para la revolución mozambiqueña. Sita Valles fue una revolucionaria angoleña que lideró una fracción extremista del MPLA (Movimiento Popular de Liberación Angoleña). Encabezará una revuelta contra el presidente Agostinho Neto líder del MPLA y después de ser derrotada ella y los suyos será salvajemente torturada y violada, para después ser fusilada. Yvonne Kane es un correlato de Sita Valles, pero también de todas las mujeres revolucionarias olvidadas por la historia.

${ }^{7}$ Instrumento de percusión tradicional en Mozambique y consistente en un madero hueco tocado con dos palos también de madera.
} 
Rita no estará en la muerte de su madre por que persigue un fantasma, a Yvonne, pero necesita exorcizarlo para reconciliarse con el pasado y es más importante la recuperación de la memoria -unida de forma indefectible a la madre- que el presente de su muerte; porque siempre la memoria está por encima de la realidad en aquellos que no tienen un pasado propio.

\section{A modo de conclusión}

El cine en Mozambique nace revolucionario y documental con la propia nación mozambiqueña, socialista y revolucionaria, y morirá con esa revolución en la simbólica pira del INC. Pero los rescoldos de ese cine vivirán en el imaginario y la memoria de dos cineastas que representan la nación y el cine de Mozambique: Licinio Azevedo y Margarida Cardoso.

La primera representación de este imaginario nace de una contradicción: uno de ellos es un extranjero que vendrá desde Brasil (Azevedo), de la mano de un mozambiqueño que ha regresado a su nación (Guerra) y que la abandonará de nuevo, de vuelta a Brasil, tras la decepción y muerte revolucionaria; ambos serán los padres involuntarios del cine mozambiqueño y, en la práctica, sus únicos testaferros. Margarida, por su parte, será una extranjera que, tras pasar su infancia y adolescencia en Mozambique, vivirá en su imaginario artístico y discursivo anclada en la melancolía, fuente de su creatividad e instrumento necesario en su intento de comprensión de la historia mozambiqueña y de sí misma. Todos ellos bucearán en la realidad y utilizaran el documental para transmitir su visión del mundo, pero al igual que el discurso revolucionario se agota, el documental mostrará sus límites para contener la creatividad de ambos cineastas (Guerra aparte). Del modo en que la nación mozambiqueña se transforma de revolucionaria a “democrática”, el cine de Azevedo y Cardoso necesitará de la ficción para poder seguir profundizando en la realidad; sin abandonar lo real, ambos buscarán en la ficción con instrumentos distintos: la reconstrucción ficcionalizada de la realidad en Azevedo, y la reflexión metalingüística sobre esa realidad a través de la memoria y sus trampas en Cardoso. 
Si la revolución implica de forma inevitable un itinerario que va de la esperanza a la desilusión, extendiendo un manto de melancolía sobre los que la vivieron, protagonizaron o sufrieron, Cardoso y Azevedo deciden hacer frente a ese itinerario a través una doble vía: con la reflexión desde la memoria individual para llegar a la colectiva o con la voluntad de testimonio crítico sobre la realidad y su recuerdo, mediante la mostración del acontecimiento en su desnudez. Caminos fructíferos, nacidos de la mirada directa del documental y que apuestan por memoria y realidad como dos caras del mismo, hermoso y emotivo trayecto.

\section{Referencias bibliográficas}

Cabaço, J. L. (2017). Notas para uma contextualizaçao do cinema moçambicano. Revista Mulemba. Rio de Janeiro: UFRJ. Vol. 9, n ${ }^{0} 17$. Janeiro-julho, pp. 90-98.

Convents, G. (2011). Os Moçambicanos perante o cinema e o audiovisual. Dockanema: Cape Town.

Da Silva, A. M. (2016). Archives, memories, and colonial resistance in the work of the Portuguese filmmakers Margarida Cardoso and Flipa Cesar. Journal of Romance Studies. Vol 16, nº 12, pp. 96-111.

Lança, M. (2015). Entrevista a Margarida Cardoso, a partir de Yvonne Kane. Buala: Cara a Cara. 5 de marzo. http://www.buala.org/pt/cara-acara/entrevista-a-margarida-cardoso-a-partir-de-yvone-kane.

Lopes, J.M. (2016). Cinema de Moçambique no pós-indepêndencia: una trajetória. Revista Brasileira de Estudios de Cinema e Audiovisual. Vol. 15, $\mathrm{n}^{0}$ 2. Julio-diciembre, pp. 1-30.

Manjate, T. (2017). Virgem Margarida e a Última Prostituta: a morte das fronteiras entre a documentário e a ficçao. Revista Mulemba. Rio de Janeiro: UFRJ. Vol. 9, no 17. Janeiro-julho, pp. 112-121.

Pereira, A. C. \& Cabecinhas, R. (2016). Um país sem imagem é un país sem memória... Entrevista con Licinio Azevedo. Estudios IberoAmericanos. Porto Alegre. Vol. 42, nº 3. Sept-dez, pp. 1026-1047.

Rincón Yohn, M. del; Torregrosa Puig, M. y Cuevas Álvarez, E. (2017). La representación fílmica de la memoria personal: las películas de memoria. Revista Zer. Vol. 22, no 42, pp. 175-188.

Santana França, A. (2017). A produçao documentarista de Licinio Azevedo: imagens, discursos e narrativas moçambicanas do pos-independência. Revista Mulemba. Rio de Janeiro: UFRJ. Vol. 9, no 17. Janeiro-julho, pp. 99-111. 
Schefer, R. (2016). Mueda, Memória e Massacre by Ruy Guerra and the Cultural Forms of the Makonde Plateu. Comunicaçao e Sociedade. Vol. 29, pp. 53-77.

Schefer, R. (2012). O nascimento da ficçao. Poiésis. Revista do Programa de Pós-Graduaçao- Mestrado. Universidade do Sul da Santa Catarina. Tubarao. Vol. 5, no 9. Jan./Jun, pp. 260-279.

Soranz Soranz, G. (2014). O Instituto Nacional de Cinema e outras expêriencias audiovisuais em Moçambique no seu período póscolonial. Contemporanea. Comunicaçao e Cultura. Vol. 12, $\mathrm{n}^{0}$ 1. Jun-abr, pp. 147-164.

Sousa Dias, V. \& Cipriano M. (2010). Entrevista Margarida Cardoso. Novas \& Velhas tendências no cinema português contemporâneo. Centro de Investigaçao em Artes e Comunicaçao (CIAC), pp. 125-136.

Stock, R. (2016). Cinema and Conflict in Postcolonial Mozambique: Archival Images as Illustration and Evidence. En Estas sao asa armas. Mediations of Disruption in Post-Conflict Cinema. Martins, A. Et al (Ed.). London, pp. 75-91.

Vieira, E. (2013). Politics and the Aesthetics of Absence in Margarida Cardoso's Cinematic Work. Hispanic Research Journal, Vol 14, n⿳0 1. february, pp. 67-85. 